\title{
Building Innovative Service Composition Based on Two-Way Selection in Cloud Manufacturing Environment
}

\author{
Jinhui Zhao (D), ${ }^{1}$ Muzi Li, ${ }^{2}$ Yu Zhou $\mathbb{D}^{3},{ }^{3}$ and Peichong Wang ${ }^{2}$ \\ ${ }^{1}$ Network Information Security Laboratory, Hebei GEO University, Shijiazhuang 050031, China \\ ${ }^{2}$ School of Information Engineering, Hebei GEO University, Shijiazhuang 050031, China \\ ${ }^{3}$ School of Electric Power, North China University of Water Resources and Electric Power, Zhengzhou 450011, China \\ Correspondence should be addressed to Jinhui Zhao; zhaojh9977@126.com
}

Received 2 November 2019; Revised 5 January 2020; Accepted 24 January 2020; Published 13 May 2020

Academic Editor: Thomas Hanne

Copyright ( $\odot 2020$ Jinhui Zhao et al. This is an open access article distributed under the Creative Commons Attribution License, which permits unrestricted use, distribution, and reproduction in any medium, provided the original work is properly cited.

In the cloud manufacturing environment, innovative service composition is an important way to improve the capability and efficiency of resource integration and realize the upgrading and transformational upgrade of the manufacturing industry. In order to build a stable innovative service composition, we propose a novel composite model, which uses two-way selection according to their cooperation to recommend the most suitable partners. Firstly, a rough number is applied to quantify the semantic evaluation. Using the expectation of cooperative condition as reference points, prospect theory is then applied to calculate the cooperative desires for both sides based on participants' psychological attitudes toward gains and losses. Next, the cooperative desires are used to establish the two-way selection model of innovative service composition. The solution is determined by using an improved teaching-learning-based optimization algorithm. Compared with traditional combined methods in the cloud manufacturing environment, the proposed model fully considers the long-neglected needs and interests of service providers. Prospect theory takes psychological expectations and varying attitudes of decision makers towards gains and losses into account. Moreover, an interval rough number is used to better preserve the uncertain information during semantic quantification. Experimental results verify the applicability and effectiveness of the proposed method.

\section{Introduction}

Since the formation of networking in the economic environment, competition for complementary advantages and optimized resources in the manufacturing industry exists not only between individual enterprises but also between the supply chain and the industrial chain. Relying on the manufacturing resource-sharing service platform to integrate and optimize the allocation of advanced manufacturing technology and production modes, creating business values with the advantage of technological resources has become a standard practice in the manufacturing industry [1]. Cloud manufacturing ( $\mathrm{CMfg})$ has emerged in recent years as a dominant sharing service platform of manufacturing resources [2,3]. Based on user requirements, CMfg organizes online manufacturing resources to provide a variety of ondemand manufacturing services for users [4]. It also simultaneously accomplishes information sharing and resource coordination among enterprises and achieves the goal of rapid response to the market. This has effectively solved numerous problems, such as high product input, a lengthy $\mathrm{R} \& \mathrm{D}$ cycle, and widespread of resources. This greatly improves the utilization rate of manufacturing resources within the group, industry, and region. The idea of cloud manufacturing emphasizes collaboration between enterprises and resource sharing within the social scope, which can maximize the sharing and on-demand use of manufacturing resources, and makes full use of manufacturing capacity and knowledge.

In the cloud manufacturing service platform, innovative service is an important way to improve the capability and efficiency of resource integration and realize the upgrading and transformational upgrade of the manufacturing operations [5]. Enterprises apply new ideas and technologies to 
improve or change existing service and product processes and to increase efficiency levels, thus creating higher value for customers $[6,7]$. With the development and maturation of the CMfg business model, numerous manufacturing resources have become available within the cloud manufacturing service platform, which provides more and greater opportunities for enterprises to innovate in-demand services and products quickly and easily. Generally, enterprises target the interests of a particular market group. The vastness of cloud manufacturing resources increases the difficulty of building innovative service composition that serves the needs of all the participants. Another concern is how initiators and participants can find satisfactory and accurate service resources quickly.

The aim of the research reported here is to improve the satisfaction levels for initiators and participants in service composition through the proposal of a novel selection model based on two-way selection. In this model, both initiators and participants are evaluated by the opposite side based on their interests and needs. The main contributions of this work are four-hold:

(i) First, in order to preserve the uncertain information in semantic evaluation, we quantify semantic evaluation to fuzzy interval values by using rough numbers [8-10]

(ii) Second, taking into account the enterprise's market position and psychological attitudes to gains and losses, we use the prospect theory $[11,12]$ to evaluate the cooperative desires of both parties

(iii) Third, according to the cooperative desires of both parties, we design the two-way selection model to construct innovative service composition, which is solved by an improved teaching-learning-based optimization algorithm (TLBO) [13-16]

(iv) Finally, we conduct comprehensive experiments to evaluate our model by employing a synthesized manufacturing service flow and validate the effectiveness of our model

The remainder of this paper is organized as follows. In Section 2, related works are presented. Section 3 introduces several relevant theoretical bases and concepts. In Section 4, a research model based on two-way selection is proposed and the resolution process is described in detail. In Section 5, the results of several experiments are reported and the implications of the findings are discussed. Finally, concluding comments and a description of necessary future research work are offered in Section 6.

\section{Related Work}

2.1. Search and Match Service. The matching problem of cloud manufacturing services is a multiattribute decision optimization problem [17]. When users retrieve services, they search for resources and services primarily by submitting task attribute requirements, which is a fuzzy retrieval of multiple properties through looking for matching data in the database and filtering it. By applying related technologies of semantic description, many existing studies formulate the search and match strategies to improve matching efficiency and construct a discovery framework of resources and services to standardize the description of resources and tasks and to facilitate the sharing and circulation of knowledge. Using the concept of "Situation" as the conceptual cornerstone and building block of descriptions, Garcia-Crespo et al. [18] proposed a conceptual model of semantic representation and knowledge reasoning in industrial manufacturing processes. But their model lacks an explanation of maintenance processes and diagnostic results and is difficult to feedback knowledge. Based on feedback control, He et al. [19] developed a dynamic update method for the attribute vector and selected cloud services with the technique for order preference by similarity to ideal solution (TOPSIS). Analyzing the essential features, classification, and the modeling requirements of CMfg tasks, Wang et al. [20] achieved the matching of tangible resources and intangible resources by establishing a cloud manufacturing framework which promoted cloud manufacturing to become the advanced manufacturing mode of the manufacturing industry. Lu et al. [21] presented an integrated networked environment to quickly allocate resources, according to policies imposed by users or providers on requests and resources, respectively. The proposed approach uses distributed knowledge for adaptive resource planning and intelligent service composition and achieves an accurate mapping between dynamic service requests and distributed manufacturing resources. Studying the relevant problems in the process of researching manufacturing service supplydemand matching, Tao et al. [22] put forward a simulator framework for manufacturing service supply-demand matching and a configurable research methodology for researchers of different levels and different research directions. To select the proper cloud manufacturing services to satisfy both sides of supply and demand, Zhao et al. [23] proposed a bilevel programming model that employed extension theory to make a multiattribute evaluation. Their proposed model introduces cooperative expectation in evaluation and recommend services by bilevel programming to make the selection result closer to the actual needs of both sides. However, it only analyzes the process of solving a single service by linear regulation and does not study the composition service under mass data. The abovementioned analysis shows that most studies mainly focus on how to select the best services, while less studies have taken demands as a reference for accurate evaluation and rarely considered the impact of decision maker's psychological attitudes in the evaluation selection process.

2.2. Optimization and Composition of Service. For task requirements of multiresource services, optimization and composition of services selects a service resource from the cloud manufacturing resource pool to meet the functional constraint requirements of each subtask and assembles the resource services in a certain order to collaboratively complete the multiresource services task. In general, the service composition problem is a multiobjective 
programming problem, which attracts a large number of scholars to study. Many studies have taken the quality of service (QoS) [24-27] as the main objective function and considered other factors such as energy consumption and cost and risk of consumers, providers, and transportation. Because of the advantages of intelligent evolutionary algorithms in generality, speed, and coding, they are widely used and studied in solving the problem for optimization and composition of services. Based on QoS and energy consumption, Xiang et al. [26] established the model of multiobjective service composition, which was mapped to group leader algorithm and solved by a novel globe optimization algorithm. Focusing on the selection of energy-efficient services and service composition, Thar et al. [27] provided a multicloud service computing approach (Cloud-SEnergy). Their approach selects the least possible number of composite services based on an effective combination of cloud services' providers that satisfy the user request. Taken a task as a directed acyclic graph, Ahn et al. [28] proposed graphbased algorithms to obtain cost, execution time, quality, and reliability of a task having multiple composition patterns and compared the performances of three metaheuristic algorithms (genetic, variable neighbourhood search, and simulated annealing) in solving the problem. In order to handle complicated many-objective problems of service composition and optimal selection in cloud manufacturing, Zhou et al. [29] improved the artificial bee colony (ABC) algorithm by introducing a new diversity maintenance strategy, a synergetic mechanism for food source perturbation, and a novel computing resources allocation scheme. However, as the number of services increases dramatically, many intelligent algorithms require more loops, produce errors, and waste resources, which make the cloud manufacturing system process cumbersome.

Moreover, from the perspective of composite services and service composite networks, Moghaddam et al. [30, 31] studied combinable relationship-based composition service network (CoRCS-Net) in composition of cloud manufacturing services and introduced the concepts of composite strength and composite strength diversity to describe the composite service invocation. Focusing on the social collaboration feature of manufacturing services, Ren et al. [32] proposed a service selection model that could maximize the overall synergy effect based on collaboration requirement. Based on task relatedness and temporal dependencies between CMfg services in workflow, Li et al. [33] presented a two-stage composition method for resourceservice chain. For multidata centers, Kendrick et al. [34] proposed a multiagent-based service composition approach for the efficient retrieval of distributed services and propagation of information within the agent network, which reduced the amount of brute-force search to improve efficiency. To detect security, privacy, and trustworthiness violations of service compositions, Asim et al. [35] presented a monitoring framework for SOA-based systems, which was only one building block of a holistic approach for the secure and trustworthy construction and execution of service compositions, but it was implemented as a stand-alone package which could be applied in diverse service orchestrating platforms.
The abovementioned studies have some theoretical significance and practical guidance to solve the manufacturing service optimization combination for complex task requirements. But supply and demand are bilateral, most studies ignore the needs and interests of service providers. Considering the diversity of collected data formats, the impact of psychology on selection, the interests and needs of both parties, and the improvement of intelligent algorithms, we study the innovative service composition from these four aspects based on QoS.

\section{Theoretical Background}

\subsection{Symbol Description}

(1) $X$ is a set, $\bar{X}$ and $\underline{X}$ represent the upper and lower limits, respectively

(2) $U$ is a universe which is a nonempty finite set, and $Y$ is an arbitrary object of $U$

(3) $R$ is a set which includes $q$ classes, $R=\left\{N_{1}, N_{2}, \ldots, N_{q}\right\}$

(4) $\operatorname{Bnd}\left(N_{i}\right)$ is the boundary region of $N_{i}$

(5) $R N\left(N_{i}\right)=\left[\underline{\operatorname{Lim}}\left(N_{i}\right), \overline{\operatorname{Lim}}\left(N_{i}\right)\right]$ is the rough number of $N_{i}, \underline{\operatorname{Lim}}\left(N_{i}\right)$ and $\overline{\operatorname{Lim}}\left(N_{i}\right)$ represent the lower and upper limits, respectively

(6) $V$ is the comprehensive prospect value, calculated by the subjective value $(v(\Delta x))$ and the decision weight $(\omega(p))$

(7) $a, \beta$, respectively, represent the coefficients of risk attitude for the decision makers on risk "preference" and "avoidance"

(8) $\gamma$ and $\delta$, respectively, represent the risk attitude coefficients of decision makers when they perceive the gains and losses

(9) $p$ is the probability of an event

(10) $d_{k}$ is the distance between the two numbers

(11) $E\left(q_{k}\right)$ is the expectation of number $q_{k}$

(12) $\sigma^{2}\left(q_{k}\right)$ is the variance of number $q_{k}$

(13) $V_{i j}$ is the cooperative desire of core enterprise for the $i^{\text {th }}$ subtask to the $j^{\text {th }}$ service; $\widetilde{V}_{i j}$ is the cooperative desire of the $j^{\text {th }}$ service to core enterprise and the $i^{\text {th }}$ subtask

(14) th is the constraint

(15) st is the student, coded $V_{i j}$ and $\widetilde{V}_{i j}$

(16) $r$ is the learning factor

(17) "Mean" is the average of academic achievement

(18) "IF" is the teaching factor

3.2. Rough Number Theory. The rough set theory, which is proposed by Pawlak in 1982 [8], is an effective tool to deal with incomplete information such as inaccuracy, inconsistency, and incompleteness, with the advantage of mature mathematical foundation and not requiring prior knowledge. Based on equivalence relation, the rough set describes 
any concept through two exact sets about upper approximate and lower approximate. When the upper and lower approximations are equal, the concept is an exact set; otherwise, it is a rough set.

Definition 1. Let $Z$ be a universe. $X$ is a set whose upper and lower approximations are defined as follows:

$$
\left\{\begin{array}{l}
\bar{X}=\bigcup_{x \in X} R(x), \\
\underline{X}=\left\{x \in Z \mid R^{-1}(x) \in X\right\},
\end{array} \quad R=(N, c, v),\right.
$$

where $R(x)=\{y \in Z \mid y \cong x\}$, and $R^{-1}(x)=\{y \in Z \mid x \cong y\}$

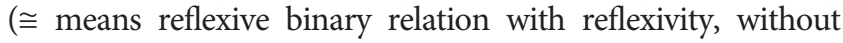
symmetry and transitivity).

Definition 2. The whole of all sets with the same lower approximation and upper approximation is called a rough set, which is presented as $(\underline{X}, \bar{X})$.

The rough number theory is the sublimation and development of the rough set theory, which is first proposed by Zhai et al. [10]. A rough number usually includes lower approximation, upper approximation, and the rough boundary interval, which only depends on the original data. Because not requiring any auxiliary information or data analysis and adjustment, it can better capture real perception of users and keep the objectivity of assessment information.

Definition 3. Suppose $U$ is a universe which is a nonempty finite set, $R$ is a set which includes $q$ classes, $R=\left\{N_{1}\right.$, $\left.N_{2}, \ldots, N_{q}\right\}$, and $Y$ is an arbitrary object of $U$. If these classes are sorted as $\left\{N_{1}<N_{2}<\cdots<N_{q}\right\}$, the upper approximation $\left(\overline{\operatorname{Apr}}\left(N_{i}\right)\right)$ and lower approximation $\left(\operatorname{Apr}\left(N_{i}\right)\right)$ of each class $N_{i}\left(N_{i} \in R, i=1,2, \ldots, q\right)$ are defined as follows:

$$
\left\{\begin{array}{l}
\overline{\operatorname{Apr}}\left(N_{i}\right)=\bigcup\left\{Y \in U / R(Y) \geq N_{i}\right\}, \\
\underline{\operatorname{Apr}}\left(N_{i}\right)=\bigcup\left\{Y \in U / R(Y) \leq N_{i}\right\} .
\end{array}\right.
$$

The boundary region $\left(\operatorname{Bnd}\left(N_{i}\right)\right)$ of $N_{i}$ is as follows:

$\operatorname{Bnd}\left(N_{i}\right)=\left\{Y \in U / R(Y)<N_{i}\right\} \cup\left\{Y \in U / R(Y)>N_{i}\right\}$.

Then, $N_{i}$ can be indicated by a rough number $R N\left(N_{i}\right)=\left[\underline{\operatorname{Lim}}\left(N_{i}\right), \overline{\operatorname{Lim}}\left(N_{i}\right)\right]$, which is determined by lower and upper limits. The lower and upper limits can be calculated by

$$
\left\{\begin{array}{l}
\overline{\operatorname{Lim}}\left(N_{i}\right)=\frac{1}{B_{U}} \sum R(Y) \mid Y \in \overline{\operatorname{Apr}}\left(N_{i}\right), \\
\underline{\operatorname{Lim}}\left(N_{i}\right)=\frac{1}{B_{L}} \sum R(Y) \mid Y \in \underline{\operatorname{Apr}}\left(N_{i}\right),
\end{array}\right.
$$

where $B_{U}$ and $B_{L}$ are, respectively, the number of objects that are included in $\overline{\operatorname{Apr}}\left(N_{i}\right)$ and $\underline{\operatorname{Apr}}\left(N_{i}\right)$.

3.3. Prospect Theory. Prospect theory is proposed by Kahneman and Tversky $[11,12]$. Prospect theory considers that people are limited rational and have various attitudes towards losses and gains in making decisions. People, in prospect theory, are more sensitive to losses than to gains, and their value functions are in the shape of "S." The prospect utility function consists of two parts:

$$
V=\sum v(\Delta x) \times \omega(p)
$$

where $\Delta x=x-x_{0}, v(\Delta x)$ is the subjective value, and $\omega(p)$ is the decision weight.

The value function given by Tversky et al. is a power function:

$$
v(\Delta x)= \begin{cases}\Delta x^{a}, & \Delta x \geq 0 \\ -\theta(-\Delta x)^{\beta}, & \Delta x<0\end{cases}
$$

where $a$ and $\beta$, respectively, represent the coefficients of risk attitude for the decision makers on risk "preference" and "avoidance" and $\theta$ is the sensitivity coefficient to losses and gains. When $0<a, \beta<1$, the larger the parameters are, the weaker the sensitivity of the decision maker is. $\theta>1$ means more aversion to losses than to gains.

The decision weights are inferred from the expected selection. It is found that there is a nonlinear relationship between the decision weight function $(\omega(p))$ and the objective probability in the expected utility, which is the ratio of the weight of probability $p$ to the weight of deterministic events. It neither conforms to the probability formula nor is understood as subjective probability. The formula given by Tversky et al. is

$$
W\left(A_{i}\right)=\omega\left(p\left(A_{i}\right)\right),
$$

where $W$ is the weight function, $\omega$ is the probability weight function under risk, $p$ is the probability of judgment, and $A_{i}$ is the $i^{\text {th }}$ event.

The $p\left(A_{i}\right)$ is given by the assessor's judgment. Considering the focus of the system application and the impact of some risk uncertainties on unknown probability events, the probability weight given by Kahneman et al.is

$$
\left\{\begin{array}{l}
\omega^{+}(p)=\frac{p^{\gamma}}{\left(p^{\gamma}+(1-p)^{\gamma}\right)^{1 / \gamma}} \\
\omega^{-}(p)=\frac{p^{\delta}}{\left(p^{\delta}+(1-p)^{\delta}\right)^{1 / \delta}}
\end{array}\right.
$$

where $\omega^{+}(p)$ and $\omega^{-}(p)$ is the nonlinear weight function of gains and losses, respectively, $\omega(0)=0$ and $\omega(1)=1$, and $\gamma$ and $\delta$, respectively, represent the risk attitude coefficients of decision makers when they perceive the gains and losses.

\section{Building Innovative Service Composition Based on Two-Way Selection}

4.1. A Research Model Based on Two-Way Selection. Suppose that an enterprise decides to develop a new product or service after market research and analysis. Due to the lack of resources or capabilities to complete the full work, the enterprise hopes to build a service composition in the cloud 
manufacturing service platform to quickly respond to the market. This enterprise, which is called core enterprise, is the initiator in innovative service composition.

$C=\left\{c_{1}, c_{2}, \ldots, c_{f}\right\}$ is a set of attributes that the core enterprise evaluates the services in the cloud manufacturing service platform. The $c_{k}$ is the $k^{\text {th }}$ index, where $k$ is in $(1,2, \ldots$ and $\mathrm{f})$ and $c_{1}, c_{2}, \ldots, c_{f}$ are, respectively, independent. $A=\left\{a_{1}, a_{2}, \ldots, a_{g}\right\}$ is an attribute set that candidates of services evaluate the innovative service and core enterprise. The $a_{t}$ is the $t^{\text {th }}$ index where $t=1,2, \ldots, \mathrm{g}$, and $a_{1}, a_{2}, \ldots, a_{g}$ are independent of each other too. The requirements of both sides of collaborators are called constraints. The constraints that must be met are called hard constraints, and the rest are called soft constraints. There are three types in soft constraints:

(1) Cost-constrained properties: the smaller their value, the better, such as the cost and the energy consumption

(2) Benefit-constrained properties: the values of this type are as big as possible, for example, the quality of service and the reliability

(3) Zone-type constraint properties: this type attributes change in a range, for instance, the manufacturing period

The research model based on two-way selection is shown in Figure 1.

After defining the structure of the product or service, the core enterprise divides the cooperative task into many subtasks according to the work process. The core enterprise clearly describes and submits the cooperative tasks and the QoS requirements of each subtask according to the market positioning of the product or service. Receiving the request, the composite service management center queries the monitoring system for the services that meet the functional requirements and calculates the cooperative desire of the core enterprise to each candidate service by prospect evaluation combining cooperative expectation and the psychological attitude towards gain and loss. While, the cooperative desires of candidate service providers to the core enterprise and project are calculated in the same way. After two-way selection, the composite service management center structures the innovative service composition and sends the requests for elected candidates. If candidates accept the invitation, a new service composition is registered in a service registration center, otherwise reselected. The core enterprise is responsible for the operation, maintenance, revocation, and coordination of new services.

4.2. Evaluation Based on Prospect Theory. In order to obtain the values about gains and losses in prospect theory, the cooperative expectations of core enterprise to each subtask and that of partner services to core enterprise and product are taken as the reference points to calculate the distances between actual values and reference values, and the values of gains and losses are calculated according to whether the attributes are the cost or benefit type.

In the evaluation process, the perceived values are expressed as three types: numeric, semantic, and interval numbers. To facilitate the calculation automatically, the semantic evaluation must be quantized firstly. According to the actual situation in this system, the comment set is divided into seven levels. Each uncertain evaluation comment corresponds to a fuzzy interval, as shown in Table 1.

For example, there are 20 evaluations of reputation for a service within a month in Table 2:

According to formula (4), $\underline{\operatorname{Lim}}\left(L_{3}\right)=\langle 0.420,0.580\rangle /$ $1=<0.420,0.580>$ and $\overline{\operatorname{Lim}}\left(L_{3}\right)=(<0.420,0.580>+<0.580$, $0.740>+<0.740, \quad 0.900>\times 8+<0.900, \quad 1.000>\times 10) / 20=$ $<0.7960,0.9260\rangle$. In the same way, the rough number $R N\left(L_{4}\right)=\{<0.500, \quad 0.660>,<0.816, \quad 0.944>\}, \quad R N\left(L_{5}\right)=$ $\{<0.692,0.852\rangle,<0.829,0.956>\}$, and $R N\left(L_{6}\right)=\{<0.796$, $0.926>,<0.900,1.000>\}$. If each assessment is equally important, the average rough number is $\{<0.721,0.866\rangle$, $<0.862,0.976>\}$. We can see that the upper limits and lower limits of quantized rough numbers are interval numbers.

Definition 4. Suppose $q_{k}=\left\{\left\langle\underline{q_{k}^{\text {low }}}, \overline{q_{k}^{\text {low }}}\right\rangle,\left\langle\underline{q_{k}^{\text {up }}}, \overline{q_{k}^{\text {up }}}\right\rangle\right\}$ is an interval rough number. Then, the expectation of $q_{k}$ is as follows:

$$
E\left(q_{k}\right)=\frac{\left(\underline{q_{k}^{\text {low }}}+\overline{q_{k}^{\text {low }}}+\underline{q_{k}^{\text {up }}}+\overline{q_{k}^{\text {up }}}\right)}{4}
$$

where the $k$ is in $\{1, \ldots, f\}$ or $\{1, \ldots, g\}$.

The variance is

$$
\sigma^{2}\left(q_{k}\right)=\frac{\left(\underline{q_{k}^{\text {low }}}-E\left(q_{k}\right)\right)^{2}+\left(\overline{q_{k}^{\text {low }}}-E\left(q_{k}\right)\right)^{2}+\left(\left(\underline{q_{k}^{\text {up }}}-E\left(q_{k}\right)\right)^{2}+\left(\overline{q_{k}^{\text {up }}}-E\left(q_{k}\right)\right)^{2}\right)}{4}
$$




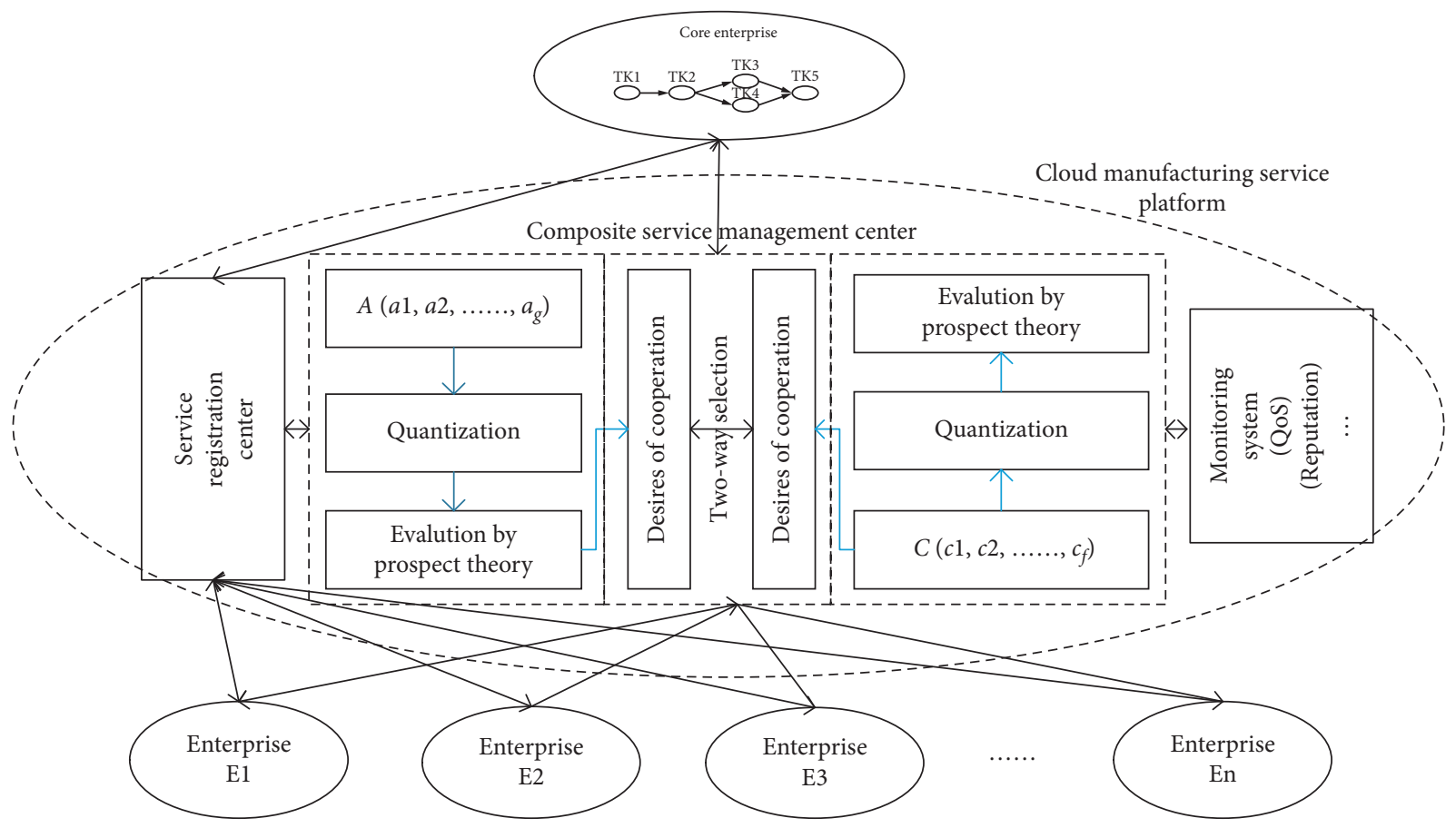

FIgURE 1: The research model based on two-way selection.

TABLE 1: The transformation relationship between evaluation semantic and fuzzy intervals.

\begin{tabular}{lccccccc}
\hline Semantic & Worst $\left(L_{0}\right)$ & Worse $\left(L_{1}\right)$ & Poor $\left(L_{2}\right)$ & General $\left(L_{3}\right)$ & Good $\left(L_{4}\right)$ & Better $\left(L_{5}\right)$ & Best $\left(L_{6}\right)$ \\
\hline Fuzzy interval & $<0.00,0.10>$ & $<0.10,0.26>$ & $<0.26,0.42>$ & $<0.42,0.58>$ & $<0.58,0.74>$ & $<0.74,0.90>$ & $<0.90,1.00>$ \\
\hline
\end{tabular}

TABLE 2: The evaluation of reputation for a service within a month.

\begin{tabular}{lccccccc}
\hline Semantic & Worst $\left(L_{0}\right)$ & Worse $\left(L_{1}\right)$ & Poor $\left(L_{2}\right)$ & General $\left(L_{3}\right)$ & Good $\left(L_{4}\right)$ & Better $\left(L_{5}\right)$ & Best $\left(L_{6}\right)$ \\
\hline Number & 0 & 0 & 0 & 1 & 1 & 8 & 10 \\
\hline
\end{tabular}

where $\sigma^{2}\left(q_{k}\right)$ is the variance between the $q_{k}$ and the expectation of $q_{k}$. numbers. The distance between two interval rough numbers is as follows:

Definition 5. Suppose $q_{k}=\left\{\left\langle\underline{q_{k}^{\text {low }}}, \overline{q_{k}^{\text {low }}}\right\rangle,\left\langle\underline{q_{k}^{\text {up }}}, \overline{q_{k}^{\text {up }}}\right\rangle\right\}$ and $e_{k}=\left\{\left\langle\underline{e_{k}^{\text {low }}}, \overline{e_{k}^{\text {low }}}\right\rangle,\left\langle\underline{e_{k}^{\text {up }}}, \overline{e_{k}^{\text {up }}}\right\rangle\right\}$ are two interval rough

$$
d_{k}=\sqrt{\frac{1}{4}\left[\left(\underline{q_{k}^{\text {low }}}-\underline{e_{k}^{\text {low }}}\right)^{2}+\left(\overline{q_{k}^{\text {low }}}-\overline{e_{k}^{\text {low }}}\right)^{2}+\left(\underline{q_{k}^{\text {up }}}-\underline{e_{k}^{\text {up }}}\right)^{2}+\left(\overline{q_{k}^{\text {up }}}-\overline{e_{k}^{\text {up }}}\right)^{2}\right]}
$$

The $q_{k}$ and $e_{k}$ are the interval rough numbers after quantization of qualitative attribute for perceived value and expected value, respectively. When $E\left(q_{k}\right) \neq E\left(e_{k}\right)$, if $E\left(q_{k}\right)>E\left(e_{k}\right), q_{k}>e_{k}$ else if $E\left(q_{k}\right)<E\left(e_{k}\right), q_{k}<e_{k}$. When $E\left(q_{k}\right)=E\left(e_{k}\right)$, if $\sigma^{2}\left(q_{k}\right)>y\left(e_{k}\right)$, then $q_{k}<e_{k}$, else $q_{k}>e_{k}$.

When the attribute values are interval numbers, this is the same as the upper limit and lower limit of the interval rough number, respectively, is a numeric value. Formula (11) degrades to formula (12):

$$
d_{k}=\sqrt{\frac{1}{2}\left[\left(q_{k}^{\text {low }}-e_{k}^{\text {low }}\right)^{2}+\left(q_{k}^{\text {up }}-e_{k}^{\text {up }}\right)^{2}\right]} .
$$

When the attribute value is numeric, the attribute value and the desired value are both real numbers, and the distance 
between the actual value and the reference value can be calculated directly:

$$
d_{k}=\left|q_{k}-e_{k}\right|
$$

Other cases can be considered as the degradation and deformation of formula (11) or formula (12).

In order to remove the influence of different dimensions on the calculation results, the distance is normalized to the value of $[0,1]$ :

$$
\tilde{d}_{k}=\frac{d_{k}}{\max \left|d_{k}\right|} .
$$

According to the type of attributes, we can establish the decision matrix of gains and losses for the core enterprise to each partner service in each subtask:

$$
T_{l}(k)= \begin{cases}\tilde{d}_{k}, & q_{k} \geq e_{k}, \\ -\tilde{d}_{k}, & q_{k}<e_{k} .\end{cases}
$$

When $q_{k} \geq \overline{e_{k}}$, the distance is regarded as the gain attribute value relative to the reference point, otherwise, it is the loss. Because there is a varying risk attitude to gain and loss in prospect theory, the attribute prospect matrix of core enterprise to partner services can be obtained from formula (6):

$$
\begin{cases}v(k)^{+}=\left(T_{l}(k)\right)^{a}, & q_{k} \geq e_{k}, \\ v(k)^{-}=-\theta\left(T_{l}(k)\right)^{\beta}, & q_{k}<e_{k} .\end{cases}
$$

Considering the decision-maker preference to each evaluation attribute and the influence of uncertain factors on unknown probability events, the weight calculation formula of the core enterprise's preference to each attribute index of the candidate service is obtained according to formula (8):

$$
\begin{cases}\omega^{+}\left(w_{k}\right)=\frac{w_{k}^{\gamma}}{\left(w_{k}^{\gamma}+\left(1-w_{k}\right)^{\gamma}\right)^{1 / \gamma}}, & v_{l}(k) \geq 0, \\ \omega^{-}\left(w_{k}\right)=\frac{w_{k}^{\delta}}{\left(w_{k}^{\delta}+\left(1-w_{k}\right)^{\delta}\right)^{1 / \delta}}, & v_{l}(k)<0 .\end{cases}
$$

Substituting the results of formulas (16) and (17) into formula (5), we can obtain the composite prospect value $\left(V_{i}\right)$ and use $V_{i}$ to represent cooperative desire of the core enterprise to the $i^{\text {th }}$ potential service. In the same way, the $\widetilde{V}_{i}$ was calculated which represents the cooperative desire of the $i^{\text {th }}$ potential service to the core enterprise and new service.

4.3. A Two-Way Selection Mathematical Model of Innovative Service Composition. According to the demand and technology, the core enterprise decomposes the tasks of new products or services to form a task flow containing multiple subtasks. Based on the existing research results [36, 37], we analyzed the manufacturing task flow and summarized the following relationships between adjacent subtasks, as shown in Figure 2:
There are usually four structures in the subtask order: serial, loop, selective, and parallel. Most of them are serial structures, and the other three structures can be simplified as an independent manufacturing link which is equivalent to serial structures. Therefore, the serial structure is as the basis to research the service composition.

The process of building innovative service composition is actually a two-way selection process between the core enterprise and the manufacturing service provider. On the one hand, the core enterprise selects the optimal service in the cloud manufacturing service platform. On the other hand, potential service providers have their own market position and cooperation intentions and decide whether to cooperate based on their views on the core enterprise and new service. Aiming to best meet the needs of both sides, we establish the mathematical model shown as follows:

$$
\begin{aligned}
& \operatorname{Max} \sum_{j=1}^{m}\left(\sum_{i=1}^{n} x_{i j} V_{i j}\right), \\
& \operatorname{Max} \sum_{j=1}^{m}\left(\sum_{i=1}^{n} x_{i j} \tilde{V}_{i j}\right), \\
& \text { s.t. } \sum_{i=1}^{n} x_{i j} \leq 1, \quad j=1,2, \ldots, m, \\
& \quad \sum_{j=1}^{m} x_{i j} \leq \theta_{i}, \quad i=1,2, \ldots, n, \\
& \quad \sum_{s_{i j} \in S} V_{i j} x_{i j} \geq t h_{i} \sum_{s_{i j} \in S} x_{i j}, \quad \forall M T_{j} \in M, \\
& \quad \sum_{M T T_{j} \in M} \tilde{V}_{i j} x_{i j} \geq t h_{j} \sum_{M T_{j} \in M} x_{i j}, \quad \forall s_{i j} \in S, \\
& \quad x_{i j}=\{0,1\}, \quad
\end{aligned}
$$

where $n$ is the number of candidate services for each subtask, $m$ is the number of subtasks, $\theta_{i}$ is the maximum number of cooperation, th is the constraints, $M$ is a manufacturing task that includes $m$ subtasks, $M=\left\{\mathrm{MT}_{1}, \mathrm{MT}_{2}, \ldots, \mathrm{MT}_{m}\right\}$, and $S$ is the set of services.

Formula (18) is the optimization function for core enterprise which selects the most satisfying service for each subtask, while formula (19) is the objective function of potential service providers to core enterprise and innovative service composition that service providers select most willing to cooperate. The constraint formula (20) indicates that the core enterprise only selects one service for a subtask, and the constraint formula (21) limits a service to participate in $\theta_{i}$ service compositions. Formula (22) limits the range of services that meet the basic constraints while formula (23) describes the market positioning and interests of service provider. In formula (24), when $x_{i j}=1$, it is selected; when $x_{i j}=0$, it is not selected. 


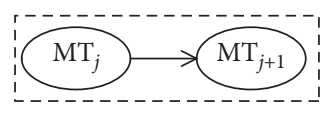

(a)

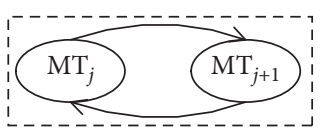

(b)

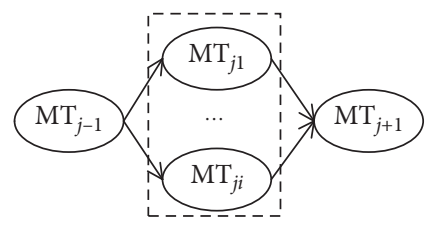

(c)

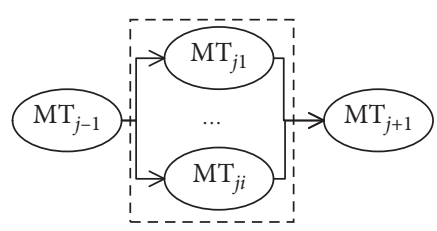

(d)

FIGURE 2: The basic structure of manufacturing task: (a) serial structure, (b) loop structure, (c) selective structure, and (d) parallel structure.

4.4. Solving Process Based on Teaching-Learning-Based Optimization Algorithm. Teaching-learning-based optimization algorithm (TLBO) is a new swarm intelligence optimization algorithm proposed by Rao et al. in 2010 [13], which simulates the teaching process of teachers to students and the learning process of students, with the aim of improving students' academic performance through the "teaching" of teachers and the mutual "learning" between students. TLBO algorithm has fewer parameters, simple algorithm, easy to understand, fast solving speed, high accuracy, and strong convergence ability, which has attracted the attention of many scholars and has been a good application in a short time. In order to improve the global convergence ability of TLBO and improve its solution accuracy, an improved TLBO is proposed in this paper based on opposition-based learning (OBL) [14].

4.4.1. Individual Coding. How to achieve the mapping between the problem about solving the two-way selection model and the individual student in the class is the first problem to be solved. In this paper, a real number coding method is adopted so that each student represents a candidate enterprise and the number of subjects is the number of subtasks, as shown in Figure 3.

4.4.2. Teaching Stage. In the teaching stage, the individual with the optimal fitness value in the class is selected as the teacher. The teacher will improve students' achievements in various subjects through teaching, and try his best to make the average grade of the class close to his own. An individual student learns according to the difference between the teacher and the average value. The updating formula of individual student [13] is

$$
\mathrm{st}_{j}^{\text {new }}=\mathrm{st}_{j}^{\text {old }}+r_{t}(\text { teacher }-\mathrm{IF} \times \text { Mean }),
$$

where $t$ is the number of iterations, "Mean" is the average of academic achievements, $r_{t}$ is the learning factor, which is a random number in $[0,1]$, and "IF" is the teaching factor, whose value is 1 or 2 :

$$
\mathrm{IF}=\text { round }(1+\text { rand }(0,1)) \text {. }
$$

4.4.3. Learning Stage. In the learning stage, each student randomly selects a learning object in the group and studies by analyzing the difference between him and other students. In the TLBO, each student adopts different learning factors, and the updating formula of student [13] is

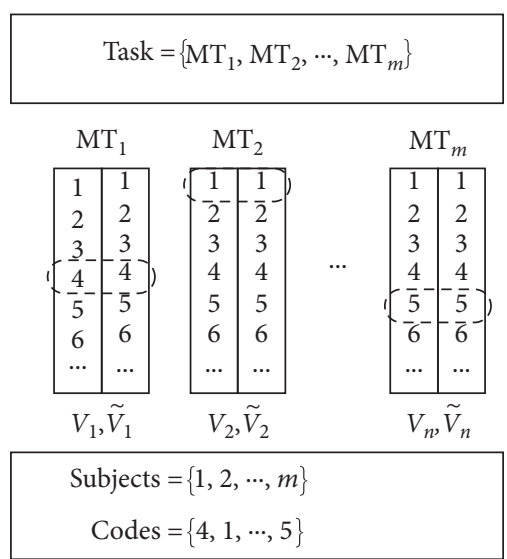

FIGURE 3: The mapping instances between services and students.

$$
\mathrm{st}_{j}^{\mathrm{new}}= \begin{cases}\mathrm{st}_{j}^{\mathrm{old}}+r_{j} \times\left(\mathrm{st}_{j}-\mathrm{st}_{k}\right), & f\left(\mathrm{st}_{j}\right)<f\left(\mathrm{st}_{k}\right), \\ \mathrm{st}_{j}^{\mathrm{old}}+r_{j} \times\left(\mathrm{st}_{k}-\mathrm{st}_{j}\right), & f\left(\mathrm{st}_{j}\right)>f\left(\mathrm{st}_{k}\right),\end{cases}
$$

where $r_{j}$ is random number in $[0,1], f\left(\mathrm{st}_{j}\right)$ and $f\left(\mathrm{st}_{k}\right)$ are individual fitness values respectively, and $s_{j}$ and $s t_{k}$ are different candidate services for a subtask.

In the process of learning, individuals should avoid learning from themselves. After learning, the $\mathrm{st}_{j}^{\text {new }}$ is better than the old one.

4.4.4. Opposition-Based Learning. The algorithm of OBL was proposed by Tizhoosh [14], whose core idea was that current student $s_{j}$ was producing the opposition population $\left(P_{j}\right)$ in the community, and the better individual went into the next generation instead of $s_{j}$ after competition between $P_{j}$ and $s_{j}$. There was a $50 \%$ higher probability of $P_{j}$ than $s_{j}$ to approach the global optimal, which was proven in detail in reference [14]. After analyzing the principle and process of OBL, it can be seen that students can improve their abilities by learning from the surrounding environment. So, we apply OBL in TLBO for students to reflect on their own problems and improve their knowledge literacy through OBL.

Definition 6. Suppose $x$ is a real number in interval $[a, b]$, the opposite number of $x$ is $x^{\prime}=a+b-x$. Then, if there is a multidimensional point $X=\left\{\begin{array}{lll}x_{1}, & x_{2}, \ldots, x_{i}, \ldots, x_{n}\end{array}\right\}$, $x_{i} \in\left[a_{i}, b_{i}\right]$, the opposite solution of $X$ is defined as $X I=\left\{x_{1}^{\prime}, x_{2}^{\prime}, \ldots, x_{i} \cdots x_{n}^{\prime}\right\}$, where $x_{i}^{\prime}=\lambda\left(a_{i}+b_{i}\right)-x_{i}$, and $\lambda$ is a random number uniformly distributed between $[0,1]$.

In the opposite-based optimization (OBO), if $f\left(X^{\prime}\right)>f(X)$, then $f\left(X^{\prime}\right)$ take the place of $f(X)$, where $X^{\prime}$ 
is the opposite solution of $X$ and the $f$ is the fitness function in the two-way selection model.

4.4.5. Solving Process. The solving process of the composition model based on two-way is described in Figure 4.

\section{Experiment and Analysis}

Since no standard test platform and test data presently exists, to verify the rationality and practicability of the proposed method, an experimental simulation environment was built in our laboratory. The development environment consists of JDK8, eclipse4.3, and SQL Server2005. Tomcat7.0 is also included as a server to build the simulation platform of cloud manufacturing services. The simulation platform was developed by Java to reproduce the establishment and management of composite services in the cloud manufacturing environment.

Suppose that a core enterprise decides to produce a new mold based on market research. According to current processing technology, the task will be divided into four relatively independent subtasks $\left[\mathrm{MT}_{1}, \mathrm{MT}_{2}, \mathrm{MT}_{3}\right.$, and $\left.\mathrm{MT}_{4}\right]$. The core enterprise can accomplish $\mathrm{MT}_{1}$, then find the other three subtasks in the cloud manufacturing service platform, and this information can be used to form an innovative service composition in response to the targeted market. Through two-way selection, based on the psychological expectation of all parties, the cloud manufacturing service platform can recommend the most suitable service to construct service composition, that all parties are willing to cooperate with. Because there are great differences between manufacturing industries, the evaluation indexes used for the various industries are also different. In this paper, the evaluation indexes for core enterprise to choose new manufacturing services include credibility, price, delivery time, and reliability, and indicators of service providers to evaluate core enterprise and new service include technical difficulty level, risk, and investment cost.

5.1. Evaluate Services Based on Prospect Theory. In order to study the impact of psychological expectation on the evaluation results, we take the $\mathrm{MT}_{2}$ as an example to analyze the evaluation process of prospect theory and compare it with the TOPSIS algorithm [19] and the extension evaluation algorithm [23]. The requirements for $\mathrm{MT}_{2}$ are (Good, 3000, [12-14], Better). There are 20 cloud-manufacturing services that meet the functional requirements with different QoS in the simulation platform. The perceived values of each service are shown in Table 3.

In Table 3, the credibility comes from the perceptive module, which collects user evaluation information periodically. The price is the cost of good reaching the demander or next manufacturing node that includes two parts: manufacturing cost and transportation cost whose unit is RMB. The transportation costs are determined by past expenses. The delivery time includes manufacturing time and transportation time, which is measured in days. In addition, the reliability is represented by the ratio of the number of satisfied tasks to the number of received tasks.

As shown in Figure 5, we take the requirements of $\mathrm{MT}_{2}$ (Good, 3000, [12-14], Better) as reference points, calculate the distance $\left(d_{k}\right)$ between the perceived value of each attribute to the reference point by formulas (9)-(13) according to the quantized format of the attribute, and normalize the $d_{k}$ using formula (14). Based on the type of attributes, the decision matrix of gains and losses $\left[T_{2}(k)\right]$ is established through formula (15).

\footnotetext{
$\begin{array}{ccccccccccc}\mathrm{S}_{1} & \mathrm{~S}_{2} & \mathrm{~S}_{3} & \mathrm{~S}_{4} & \mathrm{~S}_{5} & \mathrm{~S}_{6} & \mathrm{~S}_{7} & \mathrm{~S}_{8} & \mathrm{~S}_{9} & \mathrm{~S}_{10} & \mathrm{~S}_{11}\end{array}$ $\begin{array}{ccccccccccc}-0.471 & 0.426 & -0.858 & -0.418 & 0.493 & 0.570 & -0.415 & 0.350 & -0.238 & 0.593 & 0.392 \\ 0.443 & 0.144 & 1.000 & 0.198 & 0.526 & -0.765 & 0.731 & -0.650 & 0.781 & -0.260 & 0.388 \\ -0.126 & -0.126 & -1.000 & 0.056 & -0.360 & 0.203 & -0.439 & 0.238 & -0.439 & 0.056 & -0.126\end{array}$

$\begin{array}{llllllllllll}-0.371 & 0.597 & -1.000 & -0.437 & 0.597 & 0.597 & -0.250 & 0.456 & 0.597 & 0.597 & 0.597\end{array}$
}

In the solution of prospect theory, $\alpha=\beta=0.88$ and $\theta=2.25$ in formula (16) and $\gamma=0.61$ and $\delta=0.69$ in formula (17). Most researchers believe that these values can reflect the irrational people's preference for losses and gains. For the convenience of calculation, the weight of the core enterprise is given as $\{0.3,0.3,0.2,0.2\}$. Then, we use formula (16) to adjust the distance to the prospect value $v_{2}(k)$ and use formula (17) to adjust weight to preference weights according to $v_{2}(k)$ in $\left[T_{2}(k)\right]$. Finally, the results of formulas (16) and (17) are substituted into formula (5) to obtain the comprehensive prospect value, which is regarded as the cooperative desire. In order to analyze the differences of prospect theory in services evaluation, we compared the TOPSIS algorithm and extension evaluation method with \begin{tabular}{ccccccccc|l}
$\mathrm{S}_{12}$ & $\mathrm{~S}_{13}$ & $\mathrm{~S}_{14}$ & $\mathrm{~S}_{15}$ & $\mathrm{~S}_{16}$ & $\mathrm{~S}_{17}$ & $\mathrm{~S}_{18}$ & $\mathrm{~S}_{19}$ & $\mathrm{~S}_{20}$ & \\
-1.000 & 0.524 & 0.211 & -0.303 & -0.968 & 0.793 & -0.205 & 0.734 & 0.279 & Credibility \\
0.278 & 0.695 & 0.032 & -0.373 & 0.929 & -0.665 & 0.968 & -0.233 & 0.375 & Price \\
-0.281 & -0.281 & 0.203 & 0.056 & -0.562 & 0.556 & -0.966 & 0.056 & -0.360 & Delivery time \\
-1.000 & 0.597 & 0.308 & -0.524 & -0.710 & 0.597 & 0.597 & 0.469 & 0.597 & Reliability
\end{tabular}

the proposed algorithm in this part. The results of three methods are shown in Table 4.

From Table 4, we can get the sorting results of three methods, Prospect theory: $s_{13}>s_{11}>s_{5}>s_{2}>s_{14}>s_{19}>s_{20}$ $>s_{10}>s_{17}>s_{9}>s_{6}>s_{8}>s_{18}>s_{4}>s_{7}>s_{1}>s_{15}>s_{16}>s_{12}>s_{3}$; TOPSIS: $\quad s_{13}>s_{5}>s_{11}>s_{9}>s_{18}>s_{2}>s_{20}>s_{17}>s_{19}>s_{10}>s_{14}>$ $s_{6}>s_{7}>s_{8}>s_{1}>s_{4}>s_{16}>s_{15}>s_{3}>s_{12}$; Extension evaluation: $s_{13}>s_{5}>s_{11}>s_{2}>s_{20}>s_{9}>s_{18}>s_{10}>s_{19}>s_{14}>s_{7}>s_{6}>s_{1}>s_{4}>$ $s_{16}>s_{8}>s_{3}>s_{17}>s_{12}>s_{15}$.

There are some differences in the sorting results of these three methods. TOPSIS algorithm takes the positive ideal and negative ideal points as reference points. After the reference points are determined, there is only one sorted result for the fixed services, which follows the same sorting 


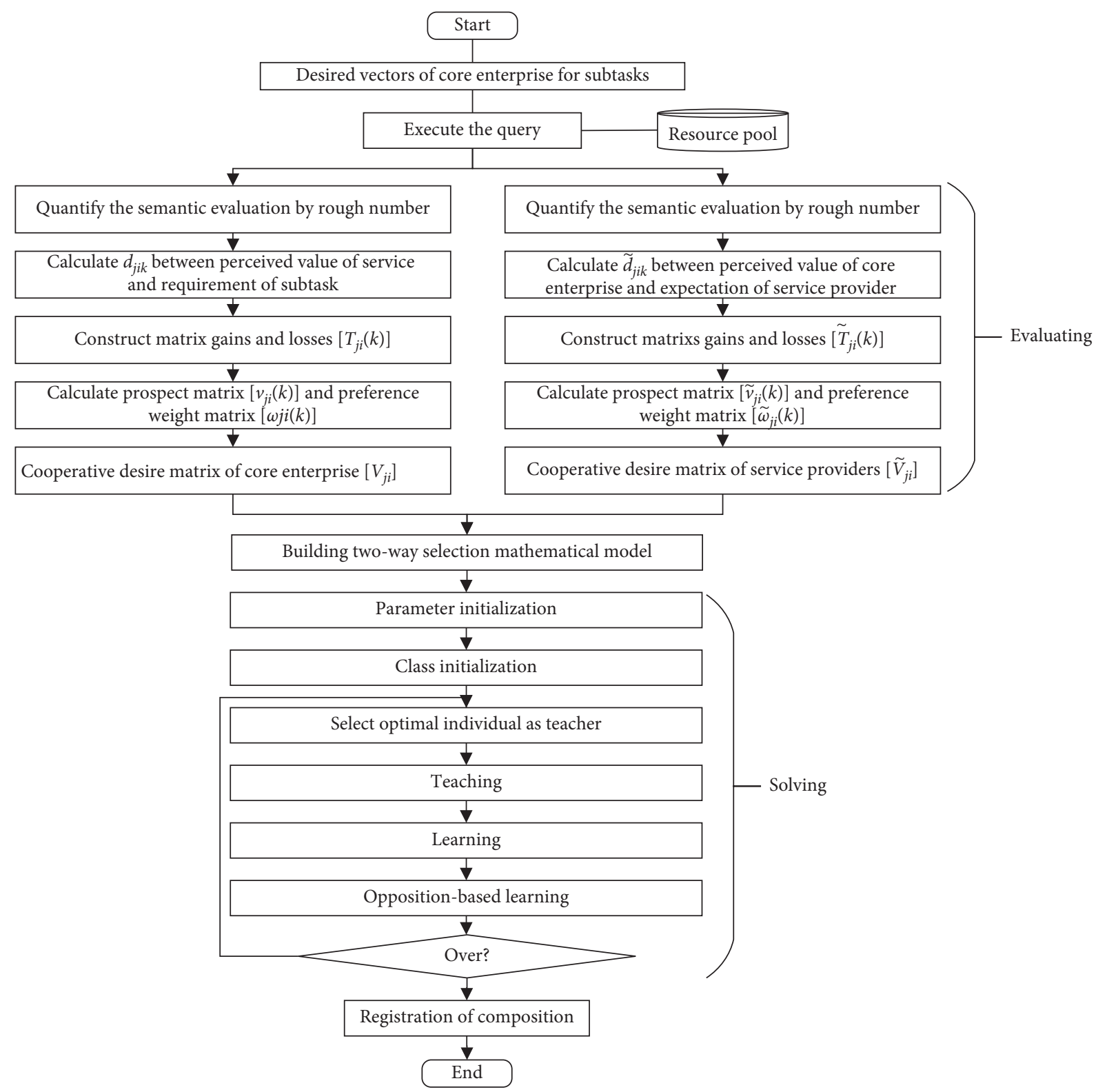

FIGURE 4: Flowchart of the proposed model.

TABle 3: The perceived values of $s_{i}$ for $\mathrm{MT}_{2}$.

\begin{tabular}{|c|c|c|c|c|c|c|c|c|c|c|c|c|}
\hline \multirow[b]{2}{*}{$s_{i}$} & \multicolumn{7}{|c|}{ Credibility } & \multicolumn{2}{|c|}{ Price } & \multicolumn{2}{|c|}{ Delivery time } & \multirow{2}{*}{ Reliability } \\
\hline & $L_{0}$ & $L_{1}$ & $L_{2}$ & $L_{3}$ & $L_{4}$ & $L_{5}$ & $L_{6}$ & Production & Transportation & Production & Transportation & \\
\hline$s_{1}$ & 0 & 1 & 4 & 9 & 6 & 0 & 0 & 2570 & 8.5 & $12-15$ & 1 & $8 / 11$ \\
\hline$s_{2}$ & 0 & 0 & 0 & 1 & 4 & 9 & 6 & 2830 & 32.7 & $9-12$ & 4 & $20 / 20$ \\
\hline$s_{3}$ & 0 & 1 & 2 & 1 & 0 & 0 & 0 & 2020 & 28.6 & $20-25$ & 3 & $5 / 10$ \\
\hline$s_{4}$ & 0 & 0 & 4 & 5 & 6 & 0 & 0 & 2800 & 11.7 & $9-12$ & 2 & $7 / 10$ \\
\hline$s_{5}$ & 0 & 0 & 0 & 0 & 1 & 5 & 2 & 2470 & 29.9 & $13-16$ & 3 & $9 / 9$ \\
\hline$s_{6}$ & 0 & 0 & 0 & 0 & 1 & 4 & 5 & 3680 & 48.0 & $4-7$ & 5 & $8 / 8$ \\
\hline$s_{7}$ & 0 & 0 & 3 & 11 & 6 & 0 & 0 & 2290 & 14.1 & $15-18$ & 2 & $16 / 20$ \\
\hline$s_{8}$ & 0 & 0 & 0 & 1 & 6 & 9 & 3 & 3580 & 38.1 & $5-7$ & 4 & $18 / 19$ \\
\hline$s_{9}$ & 0 & 0 & 0 & 18 & 4 & 9 & 0 & 2250 & 6.5 & $16-19$ & 1 & $31 / 31$ \\
\hline$s_{10}$ & 0 & 0 & 0 & 0 & 2 & 11 & 15 & 3200 & 47.6 & $6-9$ & 5 & $28 / 28$ \\
\hline$s_{11}$ & 0 & 0 & 0 & 1 & 8 & 15 & 6 & 2630 & 1.2 & $12-15$ & 1 & $30 / 30$ \\
\hline
\end{tabular}


TABLE 3: Continued.

\begin{tabular}{cccccccccccc}
\hline \multicolumn{1}{c}{ Credibility } & \multicolumn{1}{c}{ Price } & \multicolumn{2}{c}{ Delivery time } \\
$s_{i}$ & $L_{0}$ & $L_{1}$ & $L_{2}$ & $L_{3}$ & $L_{4}$ & $L_{5}$ & $L_{6}$ & Production & Transportation & Production & Transportation \\
\hline$s_{12}$ & 0 & 1 & 2 & 0 & 0 & 0 & 0 & 2700 & 35.4 & $11-14$ & 4 \\
$s_{13}$ & 0 & 0 & 0 & 0 & 1 & 4 & 3 & 2330 & 8.4 & $14-17$ & 1 \\
$s_{14}$ & 0 & 0 & 0 & 3 & 8 & 2 & 2 & 2960 & 9.9 & $8-11$ & 1 \\
$s_{15}$ & 0 & 0 & 4 & 1 & 7 & 2 & 0 & 3310 & 45.2 & $6-9$ & 5 \\
$s_{16}$ & 0 & 1 & 3 & 0 & 0 & 0 & 0 & 2110 & 6.3 & $17-21$ & 1 \\
$s_{17}$ & 0 & 0 & 0 & 0 & 0 & 0 & 2 & 3630 & 2.5 & $4-6$ & 1 \\
$s_{18}$ & 0 & 0 & 1 & 2 & 13 & 2 & 1 & 2040 & 39.0 & $18-24$ & 1 \\
$s_{19}$ & 0 & 0 & 0 & 0 & 0 & 3 & 16 & 3190 & 31.9 & $7-10$ & 4 \\
$s_{20}$ & 0 & 0 & 0 & 1 & 7 & 6 & 1 & 2610 & 33.7 & $12-15$ & 4 \\
\hline
\end{tabular}

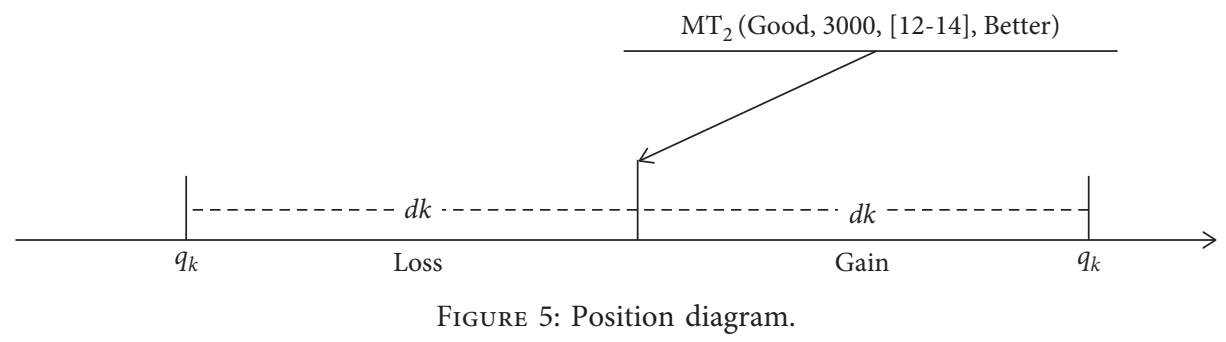

criteria for all sorts. Its evaluation result is relatively objective, but less relevant to users' requirements. The extension evaluation takes the expectation of core enterprises as the optimal points and finds out the acceptable range of core enterprises as the classical domain, which ties to the needs of each subject. So, there is a sorting result for each specific requirement. The proposed method also takes the expectation of the core enterprise as the reference points, which is an improvement of the TOPSIS method, calculates the distance between each attribute and the reference point, and considers the varying attitudes of decision makers towards gains and losses. The proposed method in this paper has a sorting result for each subject too. Extension evaluation and proposed method all embody the idea of demand as the basis for decision-making. Moreover, the proposed method takes into account people's varying psychological attitudes towards gains and losses, which interprets the psychology of decision-making and enables the optimization process to reflect human behavior.

In the abovementioned experiment, we used the suggested sensitivity coefficient $(\alpha, \beta)$ and weight coefficient $(\gamma$, $\delta$ ) in prospect theory. It is necessary to further analyze the influence of their changes. The influences of the sensitivity coefficient and weight coefficient on comprehensive prospect value are shown in Figures 6 and 7.

From Figure 5, we can see that the influences of the sensitivity coefficient in losses are more sensitive than in gains. That is say decision makers are more sensitive to losses than gains, risk-averse to the gains, and risk appetite for losses. The tow functions are same for the weight coefficient, and the key is the parameter values from experiences. Based on simulation analysis, the values of the abovementioned parameters are within a reasonable range in the calculation process of this study. But there were varying psychologies for difference decision makers, so we need to subdivide small groups in the future to determine precise parameters and provide fine services for different small groups.

5.2. Two-Way Selection Based on OBL-TLBO. We then analyze the application of OBL-TLBO in two-way selection. Let $\operatorname{Max}\left(V_{2 j}+V_{3 j}+V_{4 j}\right)$ and $\operatorname{Max}\left(\widetilde{V}_{2 j}+\widetilde{V}_{3 j}+\widetilde{V}_{4 j}\right)$ be the fitness function where $V_{2 j}, V_{3 j}$, and $V_{4 j}$ are the cooperative desires of the core enterprise to each potential service for $\mathrm{MT}_{2}, \mathrm{MT}_{3}$, and $\mathrm{MT}_{4}$ and $\widetilde{V}_{2 j}, \widetilde{V}_{3 j}$, and $\widetilde{V}_{4 j}$ are the cooperative desires of each service provider to the core enterprise and related subtask. The core enterprise selects a service for each subtask and each candidate service has the opportunity further collaboration. In order to show the advantages of improved teaching and learning algorithms (OBL-TLBO), we compare it with standard TLBO [15] and feedback elitist TLBO [16]. The problem size is designed at $20 \times 20 \times 20,100 \times 100 \times 100$, and $500 \times 500 \times 500$, that is, to say each subtask $\left(\mathrm{MT}_{2}, \mathrm{MT}_{3}\right.$, and $\left.\mathrm{MT}_{4}\right)$ has 20,100 , and 500 candidate services. At population size is $30 \times 3$, Figures $8-10$ show the convergence curves in three cases, respectively.

As seen from Figures 8-10, three algorithms find almost same optimal solutions at different sizes, and the OBL-TLBO is obviously superior to standard TLBO and elitist TLBO in convergence speed and accuracy of optimal solution. Elitist TLBO strengthens the search ability by using the elite substitution strategy and enhances the convergence ability by keeping the best elite individual to the next generation. On this basis, OBL-TLBO enhances learning ability by performing OBL, which has been indicated by Tizhoosh that there is a $50 \%$ higher probability than old one to closer to the global optimal. So, OBL-TLBO is easier to jump out of the local optimum and has a faster convergence speed. The 


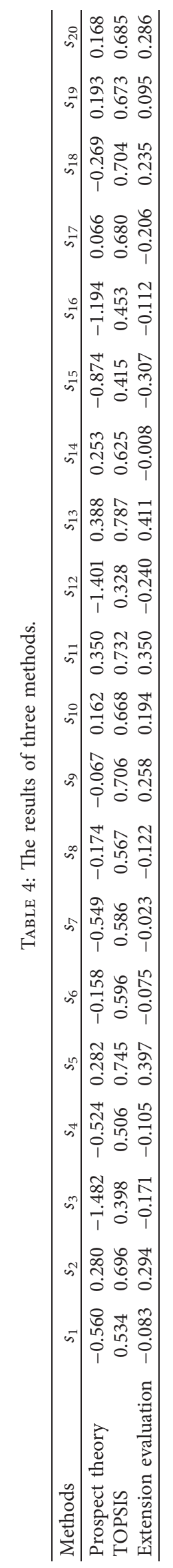




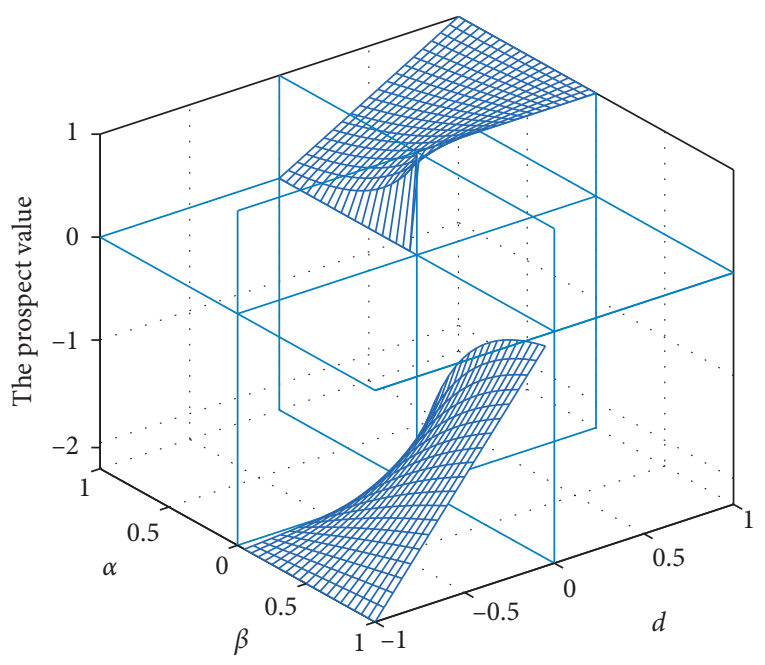

FIGURE 6: The influence of sensitivity coefficient on the prospect value.

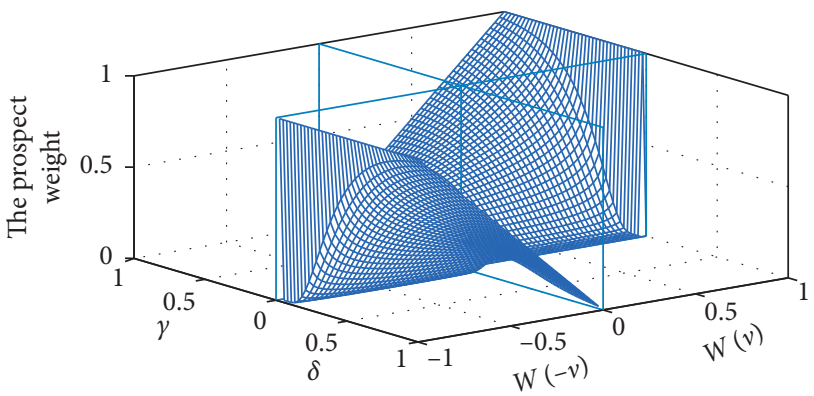

FIgURE 7: The influence of the weight coefficient on the prospect value.

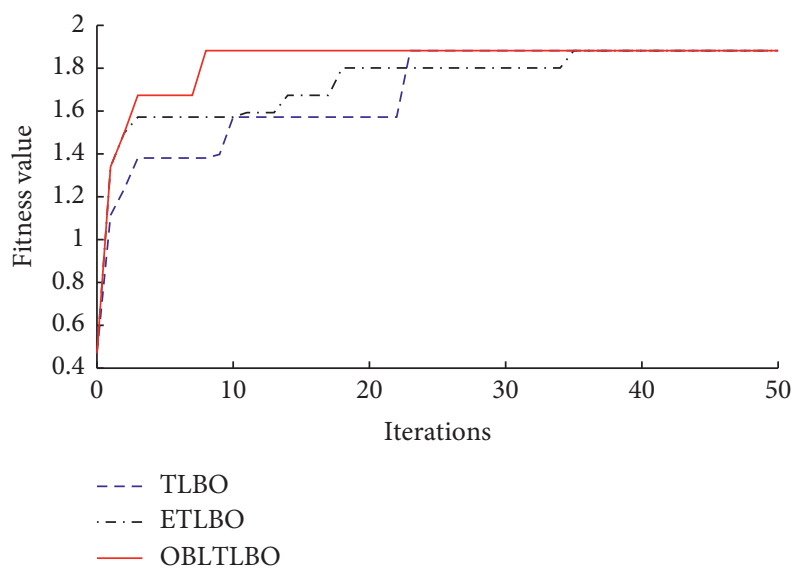

Figure 8: Convergence curves for the three algorithms in size of $20 \times 20 \times 20$.

convergence curves of OBL-TLBO in Figures 8-10 also show more variation and faster convergence than others.

On three sizes, the program of each algorithm is ran independently 20 times, and Table 5 shows the average number of iterations of three methods to obtain the optimal solution.

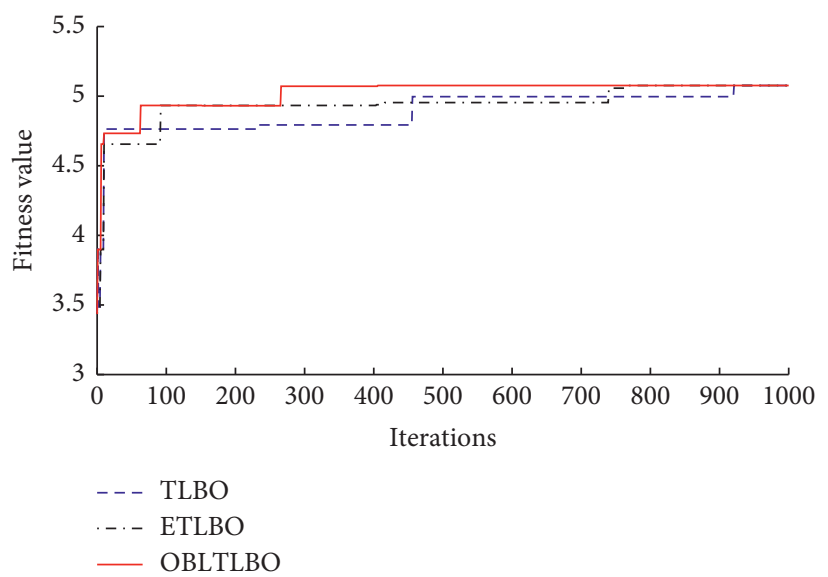

FIGURE 9: Convergence curves for the three algorithms in size of $100 \times 100 \times 100$.

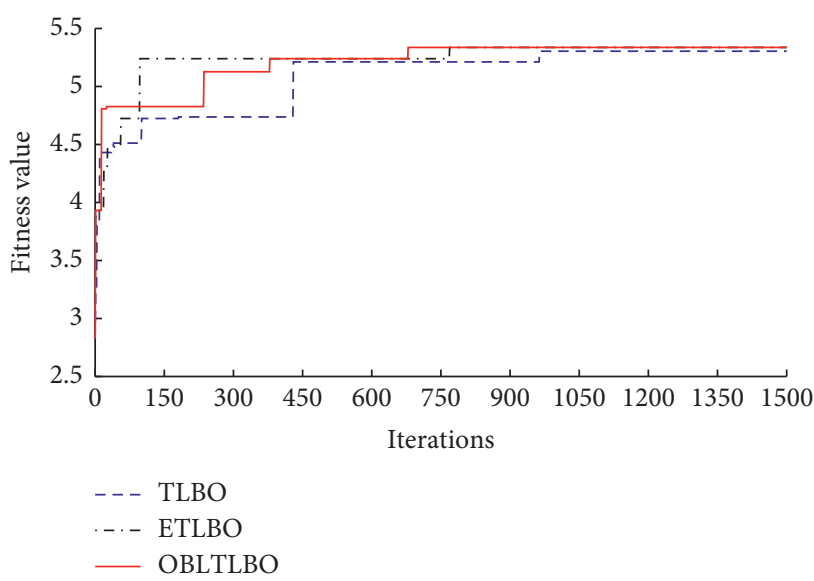

FIGURE 10: Convergence curves for the three algorithms in size of $500 \times 500 \times 500$.

TABLE 5: The average number of iterations for the three methods.

\begin{tabular}{lccc}
\hline & $20 \times 20 \times 20$ & $100 \times 100 \times 100$ & $500 \times 500 \times 500$ \\
\hline TLBO & 34 & 885 & 1162 \\
ETLBO & 33 & 772 & 1047 \\
OBL-TLBO & 18 & 453 & 918 \\
\hline
\end{tabular}

From Table 5, we can see that the performance of each algorithm is stable at different scales, and the average number of iterations for OBL-TLBO is much less than the other two algorithms.

Moreover, we analyze the influences of one-way and two-way recommended on innovative service composition. The cooperative expectations of candidate services are evaluated by four indicators: credibility, technical difficulty level, risk, and investment cost. The gaps between the actual situations and cooperation expectations for both sides in the one-way and two-way recommended mode at size of $20 \times 20 \times 20$ are shown in Table 6 , which are evaluated by prospect theory. 
TABLE 6: The gaps between the actual situations and cooperation expectations.

\begin{tabular}{ccccccc}
\hline & \multicolumn{2}{c}{ One-way recommended } & \multicolumn{3}{c}{ Two-way recommended } \\
& MT1 & MT2 & MT3 & MT1 & MT2 & MT3 \\
\hline$V$ & 0.388 & 0.362 & 0.392 & 0.280 & 0.251 & 0.383 \\
$\widetilde{V}$ & -1.424 & -1.541 & 0.999 & 0.369 & 0.184 & 0.415 \\
\hline
\end{tabular}

As can be seen from Table 6, in the one-way service combination optimization process, the recommended service for each subtask is the best one that core enterprises consider, so the value of " $V$ " is very high while the providers of recommended services are reluctant to the core enterprise and the project, so $\widetilde{V}$ is negative and lower. But, in the two-way service combination optimization process, the recommended services for the core enterprise are considered better by the core enterprise. At the same time, the providers of candidate services are also willing to cooperate and have the good evaluations, so $V$ and $\widetilde{V}$ are positive numbers and larger. And, formulas (22) and (23) prevent the occurrence of some extreme conditions and reduce the amount of calculation.

Building innovative service composition is a two-way negotiation process. Each enterprise has its own market positioning and has some requirements for partners and cooperative projects. Enterprises with good conditions are naturally required to cooperate with higher requirements while ordinary enterprises are also willing to cooperate with enterprises with the same market positioning. The "best" one is not necessarily the "most suitable" one. Mutual satisfaction between the two sides of the composite service is the basis for stable, harmonious, and healthy development. From the abovementioned analysis, it can be seen that the proposed model based on two-way is more consistent with the actual application environment of CMfg. In addition, in the process of building innovative service composition, the varying attitudes of all parties to "gains" and "losses" are fully considered, which makes the choice more suitable for the limited rationality of human beings.

\section{Conclusion}

The cooperative desires of both partners are imperative for building an innovative service composition in the cloud manufacturing environment and provide the main basis for optimization and composition of services. Based on the existing research results, this paper proposes a two-way selection method, taking cooperative desires as the maximum optimization objective. Compared with previous studies, the proposed model has the following characteristics:

(1) Because of the advantage of mature mathematical foundation and not requiring prior knowledge, we use rough numbers to quantify semantic evaluation into fuzzy interval values. The result of semantic evaluation is transformed into a rough number whose upper and lower limits are intervals. This method minimizes the loss of uncertain information in the process of semantic evaluation quantification and extends the application range of rough numbers.
(2) According to the different data formats, we have designed different calculation methods for distance. Taking demands as the reference points, we construct the loss-benefit matrix, use prospect theory to evaluate services, and analyze the influences of parameter changes on the evaluation results. Such evaluation results are more in line with people's way of thinking.

(3) With the cooperation desire of both parties, we have constructed a two-way selection model so that the recommended services can meet the needs of both suppliers and demanders, and the composed innovative services will also be stable. This method overcomes the shortcomings of traditional composition methods that have long neglected the needs and interests of service providers.

(4) Opposition-based learning greatly improves the learning ability of students and improves the efficiency of teaching and learning algorithms. It shows better results in solving the two-way selection model.

Analysis of the process of constructing innovative service composition in a mold enterprise provides verification of the proposed model's effectiveness and feasibility. The other experiments were tested in smart device and software development services and achieved good results. However, in the application of the proposed model, the complex task flow is simplified into a linear structure and relatively independent subtasks, and the complex task flows and service compositions with dependencies and constraints need further study. Future extensions about this work include potential constraints of subtasks and other complex service composition scenarios, such as time constraint, technology dependence, regional restrictions, and social relationships. Other future research avenues include the quantification of heterogeneous network data and efficient optimization algorithm.

\section{Data Availability}

The data used to support the findings of this study are available from the corresponding author upon request.

\section{Conflicts of Interest}

The authors declare that there are no conflicts of interest regarding the publication of this paper.

\section{Acknowledgments}

This paper was supported by the National Natural Science Foundation of China (Grant no. U1504622), Key Subjects of Social Science Development in Hebei Province (Grant nos. 201602020215 and 201802020211), and Science and Technology Research and Development Program in Shijiazhuang (Grant no. 191130561A).

\section{References}

[1] H. D. William and S. M. Micharl, The Virtual Corporation Structuring and Revitalizing the Corporation for the 21st Century, Harper Business, New York, NY, USA, 1993. 
[2] X. Xu, "From cloud computing to cloud manufacturing," Robotics and Computer-Integrated Manufacturing, vol. 28, no. 1, pp. 75-86, 2012.

[3] K.-B. Ooi, V.-H. Lee, G. W.-H. Tan, T.-S. Hew, and J.-J. Hew, "Cloud computing in manufacturing: the next industrial revolution in Malaysia?" Expert Systems with Applications, vol. 93, no. 3, pp. 376-394, 2018.

[4] F. Tao, L. Zhang, V. C. Venkatesh, Y. Luo, and Y. Cheng, "Cloud manufacturing: a computing and service-oriented manufacturing model," Proceedings of the Institution of $\mathrm{Me}$ chanical Engineers, Part B: Journal of Engineering Manufacture, vol. 225, no. 10, pp. 1969-1976, 2011.

[5] L. I. Changyun, W. Linlin, K. Hongyu et al., "Research on the mechanism and paths of cloud manufacturing platform service innovation," Science and Technology Management Research, vol. 36, no. 23, pp. 202-215, 2016.

[6] S. Karim and W. Mitchell, "Innovating through acquisition and internal development," Long Range Planning, vol. 37, no. 6 , pp. 525-547, 2004.

[7] C. A. I. O'Reilly and M. Tushman, "Ambidexterity as a dynamic capability: resolving the innovator's dilemma," Research Papers, vol. 28, pp. 185-206, 2007.

[8] Z. A. Pawlak, "Rough sets," International Journal of Computer \& Information Sciences, vol. 11, no. 5, pp. 341-356, 1982.

[9] R. Slowinski and D. Vanderpooten, "A generalized definition of rough approximations based on similarity," IEEE Transactions on Knowledge and Data Engineering, vol. 12, no. 2, pp. 331-336, 2000.

[10] L.-Y. Zhai, L.-P. Khoo, and Z.-W. Zhong, "A rough set enhanced fuzzy approach to quality function deployment," The International Journal of Advanced Manufacturing Technology, vol. 37, no. 5-6, pp. 613-624, 2008.

[11] D. Kahneman and A. Tversky, "Prospect theory: an analysis of decision under risk," Econometrica, vol. 47, no. 2, pp. 263-291, 1979.

[12] A. Tversky and D. Kahneman, "Advances in prospect theory: cumulative representation of uncertainty," Journal of Risk and Uncertainty, vol. 5, no. 4, pp. 297-323, 1992.

[13] R. V. Rao, V. J. Savsani, and D. P. Vakharia, "Teachinglearning-based optimization: a novel method for constrained mechanical design optimization problems," Computer-Aided Design, vol. 43, no. 3, pp. 303-315, 2011.

[14] S. Mahdavi, S. Rahnamayan and K. Deb, Opposition based learning: a literature review," Swarm and Evolutionary Computation, vol. 39, no. 2018, pp. 1-23, 2018.

[15] J. Hong, Y. Xifan, Y. Zhou, and L. Shengping, "Manufacturing cloud service composition of teaching-learning based optimization," Computer Integrated Manufacturing Systems, vol. 24, no. 1, pp. 43-52, 2018.

[16] Y. Kun-Jie, W. Xin, and W. Zhen-Lei, "Elitist teachinglearning-based optimization algorithm based on feedback," Acta Automatica Sinica, vol. 40, no. 9, pp. 1976-1983, 2014.

[17] L. Zhu and Y. Zhao, "Model of resource package, publication and discovery based on RVCS in cloud manufacturing," Computer Integrated Manufacturing System, vol. 18, no. 8, pp. 1829-1838, 2012.

[18] A. Garcia-Crespo, B. Ruiz-Mezcua, J. L. Lopez-Cuadrado, and J. M. Gomez-Berbis, "Conceptual model for semantic representation of industrial manufacturing processes," Computers in Industry, vol. 61, no. 7, pp. 595-612, 2010.

[19] X. Q. He and Y. H. Wang, "Service selection algorithm based on dynamic assessment for web of things," Acta Electronic Sinica, vol. 41, no. 1, pp. 117-122, 2013.
[20] T. Wang, S. Guo, and C.-G. Lee, "Manufacturing task semantic modeling and description in cloud manufacturing system," The International Journal of Advanced Manufacturing Technology, vol. 71, no. 9-12, pp. 2017-2031, 2014.

[21] Y. $\mathrm{Lu}$ and X. Xu, "A semantic web-based framework for service composition in a cloud manufacturing environment," Journal of Manufacturing Systems, vol. 42, pp. 69-81, 2017.

[22] F. Tao, J. Cheng, Y. Cheng, S. Gu, T. Zheng, and H. Yang, "SDMSim: a manufacturing service supply-demand matching simulator under cloud environment," Robotics and ComputerIntegrated Manufacturing, vol. 45, no. 6, pp. 34-46, 2017.

[23] J. Zhao and Y. Zhou, "Bi-level programming model of cloud manufacturing services based on extension theory," Mathematical Problems in Engineering, vol. 2018, Article ID 9702910, 13 pages, 2018.

[24] D. Mourtzis and E. Vlachou, "Cloud-based cyber-physical systems and quality of services," The TQM Journal, vol. 28, no. 5, pp. 704-733, 2016.

[25] H. Wang, P. Ma, Q. Yu, D. Yang, J. Li, and H. Fei, "Combining quantitative constraints with qualitative preferences for effective non-functional properties-aware service composition," Journal of Parallel and Distributed Computing, vol. 100, pp. 17-84, 2017.

[26] F. Xiang, Y. Hu, Y. Yu, and H. Wu, "QoS and energy consumption aware service composition and optimal-selection based on pareto group leader algorithm in cloud manufacturing system," Central European Journal of Operations Research, vol. 22, no. 4, pp. 663-685, 2014.

[27] B. Thar, A. Bandar, A. Muhammad et al., "Cloud-SEnergy: a bin-packing based multi-cloud service broker for energy efficient composition and execution of data-intensive applications," Sustainable Computing: Informatics and Systems, vol. 19, pp. 242-252, 2018.

[28] G. Ahn, Y. J. Park, and H. Sun, "Performance computation methods for composition of tasks with multiple patterns in cloud manufacturing," International Journal of Production Research, vol. 57, no. 2, pp. 517-530, 2018.

[29] J. Zhou, X. Yao, Y. Lin, F. T. S. Chan, and Y. Li, "An adaptive multi-population differential artificial bee colony algorithm for many-objective service composition in cloud manufacturing," Information Sciences, vol. 456, no. 8, pp. 50-82, 2018.

[30] F. Tao, H. Guo, L. Zhang, and Y. Cheng, "Modelling of combinable relationship-based composition service network and the theoretical proof of its scale-free characteristics," Enterprise Information Systems, vol. 6, no. 4, pp. 373-404, 2012.

[31] M. Moghaddam and S. Y. Nof, "Collaborative service-component integration in cloud manufacturing," International Journal of Production Research, vol. 56, no. 1-2, pp. 1-15, 2018.

[32] M. Ren, L. Ren, and H. Jain, "Manufacturing service composition model based on synergy effect: a social network analysis approach," Applied Soft Computing, vol. 70, pp. 288-300, 2018.

[33] H. Li, K. Chan, M. Liang, and X. Luo, "Composition of resource-service chain for cloud manufacturing," IEEE Transactions on Industrial Informatics, vol. 12, no. 1, pp. 211-219, 2015.

[34] P. Kendrick, T. Baker, Z. Maamar et al., "An efficient multicloud service composition using A distributed multiagentbased, memory-driven approach," IEEE Transactions on Sustainable Computing, 2018. 
[35] M. Asim, A. Yautsiukhin, A. D. Brucker et al., "Security policy monitoring of BPMN-based service compositions," Journal of Software: Evolution and Process, vol. 30, no. 3, 2018.

[36] S. Yi, M. Tan, Z. Guo et al., "Manufacturing task decomposition optimization in cloud manufacturing service platform," Computer Integrated Manufacturing Systems, vol. 21, no. 8, pp. 2201-2212, 2015.

[37] B. Bei-Fang, Y. Yu, L. I. Fei et al., "Decomposition model in product customization collaborative development task," Computer Integrated Manufacturing Systems, vol. 20, no. 7, pp. 1537-1545, 2014. 